\title{
THE JUBILEE OF THE THERMIONIC VALVE
}

$\mathrm{O}^{\mathrm{N}}$ N November 16, 1904, Prof. J. A. Fleming first described, in British Patent Specification No. 24850 , the application of a two-electrode thermionic valve to the rectification of alternating currents of high or, as we now term them, radio frequencies. The jubilee of this invention was celebrated on November 16 last at a special meeting of the Institution of Electrical Engineers, at which lectures on the history and development of thermionic devices were given, and an exhibition of some 240 different types of valves was opened. The widespread interest in the occasion was evident from the fact that the members present filled to capacity the lecture theatre of the Institution.

Earlier in the day, the Marquess of Salisbury, Lord President of the Council, unveiled a plaque to the memory of Sir Ambrose Fleming, F.R.S., at University College, London, the birthplace of the valve, where Fleming was professor of electrical engineering during 1885-1926. Lady Fleming was present at this ceremony, at which Lord Salisbury recalled that this invention of the thermionic valve was the starting-point for the vast developments of the present day in the field of electronics.

During the period November 16-18, an exhibition was held in the Electrical Laboratories of University College, at which wore displayed a large and historical collection of lamps, valves and electrical measuring equipment which, together with laboratory and lecture manuscript notebooks and a collection of published works, represented Fleming's wide range of interests and great contributions to electrical engineering. It was very appropriate that the exhibition should include demonstrations of current research in progress in the College laboratories, illustrating new techniques for measurement at very high radio frequencies and the study of wave propagation along conducting surfaces.

The meeting at the Institution of Electrical Engineers was opened by Lord Salisbury, who directed attention to the significance of the discovery of the thermionic valve by Sir Ambrose Fleming, whose inspiration carried him far beyond the work of previous investigators and so enabled him to add further lustre to the record of British scientists. Lord Salisbury referred to the fact that the birth of the thermionic valve was one of the most far-reaching events of the past half-century; and he directed attention to the remarkable technological applications to which the principle of the valve pointed the way. Wireless transmission, broadcasting, television, radar and radio aids to navigation and surveying, he pointed out, have all been exploited within the past few decades; and we appear to be only just at the beginning of a vast new era of the application of electronies to industrial techniques and processes. Many of the necessary processes of modern industry - sorting, testing, measuring, etc.-are fatiguing and boring tasks, and much progress has been made, particularly in the United States, in exploiting the new techniques, which open up a vista of relief from exhaustion and increased leisure for the whole working population. Lord Salisbury concluded his address with the following remarks: "Let us, then, regard this jubilee not only as an occasion for looking back with thanks and admiration to Sir Ambrose
Fleming for all that we owe him, and with gratitude to those who have followed him, but also as an occasion for looking forward, for straining forward, towards that land of promise which his genius has brought within our sight, and almost within our grasp".

The president of the Institution, Mr. J. Eccles, then welcomed Lady Fleming and expressed the hope that she would find that the large number of members present had assembled in a sincere effort to pay tribute to the great work of her late husband.

Prof. G. W. O. Howe then delivered a lecture entitled "The Genesis of the Thermionic Valve", in the early part of which he outlined Fleming's early life and education at the University of London and later at Cambridge, where he studied under Clerk Maxwell. While holding an appointment with the Edison Electric Light Co., Fleming visited the United States in 1884, when Edison exhibited an interesting discovery which he had made the year before. He had fixed a metal plate in the bulb of a carbon filament lamp, and he found that a current flowed through a galvanometer connected between the metal plate and the positive terminal of the filament. No current was indicated, however, when the connexion was made to the negative terminal of the filament. 'This phenomenon, which was afterwards known as the 'Edison effect', was applied to the control of the mains voltage in a power station, but Edison made no use of it for telegraphy. This matter greatly interested Fleming and he conducted several investigations on it from 1890 onwards, in the course of which he showed that a similar but smaller effect was obtained when platinum was used instead of carbon for the incandescent filament.

Nearly ten years later, when Fleming had become scientific adviser to the Marconi Co., he had much to do with the design and equipment of the wireless station at Poldhu, from which the first trans-Atlantic signals were transmitted in December 1901. It was in October 1904, twenty years after his visit to the United States, that it suddenly occurred to him that the Edison effect could be used for rectifying or 'detecting' alternating currents of high frequency, such as those occurring in the circuits of a wireless receiver. After making some confirmatory experiments, Fleming, at the age of fifty-five, applied for a patent for the two-electrode thermionic valve on November 16, 1904. This valve, or diode as we now term it, could be in several forms; but each of these comprised a filament, which could be heated to incandescence, and an insulated metal electrode, both sealed inside an evacuated envelope. Fleming found later that better results in the detection of wireless signals could be obtained when the valve was constructed with a tungsten filament and an insulated copper cylinder surrounding it. Almost concurrently, Wehnelt had noted that if a filament was coated with certain oxides, the emission of electrons was greatly facilitated; hence currents could be obtained with a lower temperature, with corresponding greater sensitiveness and convenience of operation.

The next step in the evolution of the thermionic valve was made by Dr. Lee de Forest, who had been working in the United States on similar lines to Fleming. In 1906, de Forest applied for a patent for 
a three-electrode valve as a device for amplifying feeble electric currents, by using a voltage on the grid or intermediate electrode to control the current flowing to the plate or anode. A few months later, the patent was extended to cover the use of the three-electrode valve, or 'audion' as de Forest termed it, as a detector of oscillations in a wireless telegraphy receiver.

After these events, a period of several years elapsed before the thermionic valve, in either its two- or three-electrode form, found any great practical use in the reception of wireless signals. This was partly due to the fact that the technique of the production of high vacua had to be considerably improved before valves could be made and used with anything like a reliable performance; but it was also due to the advanced development of such reliable and sensitive devices as the magnetic and crystal detectors. It was about 1913 before H. J. Round in Britain and other workers in the United States began successfully to apply the valve to wireless reception; and it was really during the First World War that the development of the 'hard' or high-vacuum valve was applied successfully on a large scale to the amplification of audio- and radiofrequency currents in radio reception.

T'he story was continued in a lecture on "Thermionic Devices from the Development of the Triode up to 1939" by Sir Edward Appleton, who emphasized the fact that de Forest's objective was to obtain a sensitive and controllable detector, for which purpose it was considered essential that there should be some residual gas in the audion. Sir Edward pointed out that in the basic de Forest patent, granted in 1908, a radio-receiving circuit is shown with a grid condenser, and this is deemed to be the invention of what is now called cumulative grid rectification. But it still needed some years of investigation by other workers before the mode of action of the threeelectrode valve and its remarkable potentialities were fully recognized. Notable in this phase of development was the work of E. H. Armstrong, who described, in papers published during 1914-15, experiments which did so much to elucidate the function of the triode as a detector and to show the advantage of applying back coupling or retro-action to reinforce the oscillations. $\mathrm{He}_{\Theta}$ also dealt with the use of the three-electrode valve as a generator of oscillations and for reception on the heterodyne beat principle. Armstrong took advantage of the work of Langmuir in obtaining valves with a very high vacuum, and in consequence he found it necessary to use a high-resistance shunt to the grid condenser in order to control the 'squegging' action, which was sometimes troublesome in the reception of signals with hard valves.

In the meantime, workers in other countries were not idle: following a patent in 1911, von lieben and Reisz described a soft three-electrode valve containing mercury vapour and its use as a relay or amplifier. The British pioneer workers, H. J. Round and C. S. Franklin, after experimenting with these and other soft valves, approciated the advantages of the high vacuum and produced some notable valves which achieved an outstanding reputation at the beginning of the First World War. Following the lead when the Americans entered the War in Europe, the French workers under General Ferrié developed the celebrated $R$-type hard valve, which had a cylindrical anode and a spiral grid, the filament being along the axis of both.
By the end of the War, the three-electrode valve, or triode, was really understood; but it was the only valve in common use as a detector, amplifier or generator of high-frequency oscillations. Broadcasting was, in fact, started with the triode, although its limitations were by that time well recognized. To reduce the unwanted inter-electrode coupling between grid and anode, A. W. Hull suggested the insertion of another electrode; and it remained for Round to introduce the screen-grid valve, or tetrode, into practical use in 1926. This brought under consideration the phenomenon of secondary emission from the anode; to reduce this, the insertion of a suppressor grid was proposed by B. D. H. Tellegen, of the Philips organization in Holland, who thus became the inventor of the pentode, a valve which has since become very popular for many purposes.

During the period up to 1939 , the two-electrode valve of Fleming had been employed almost solely as a rectifier for alternating currents at power frequency; but near the end of this period, this diode came back into use as a high-frequency detector ; and also, by means of a suitable circuit, as an automatic control of the grid bias on the 'variable mu' type of valve, permitting the output from the receiver to be maintained at a sensibly constant level.

In the later portion of his lecture, Sir Edward referred to the use of the thermionic valve as an electrical instrument. While ordinary triodes were found very suitable for use in, for example, E. B. Moullin's valve voltmeter, it required special design to produce an electrometer triode with a low input capacity and a very high insulation resistance for the grid. Such valves have, however, been found very useful for a number of purposes such as the study of the change in the earth's electric field due to lightning flashes. In the period up to 1939 , the valve had become a most versatile and important tool in many fields of scientific research, quite apart from its application to radio communication, broadcasting and television.

At the evening session of the meeting at the Institution, Dr. J. Thomson gave a lecture on "Developments in Thermionic Devices since 1939". It was first pointed out that during the period under review the valve has undergone extensive development, not only for radio reception, but also as an amplifier to give a steadily increasing power output in transmitters of all types. But the uses of the valve have now become very widespread; and in analysing the functions of thermionic devices in modern electronic equipment, Dr. Thomson directed attention to the fact that the valve is like an engine, performing the same duties in the electronic machine as the steam or internal combustion engine in the mechanical machine. The unique property of the electronic device is its high speed of operation. This has been exploited by the radio scientist in the development and use of microwave systems; while others are using valves for control and computing mechanisms.

Dr. Thomson made specific reference, with the aid of slides, to the various types of valve now in use for the generation and reception of centimetre-wave frequencies; and gave an explanation of the action of the klystron and its analogous relationship with the travelling-wave tube and the magnetron. He also illustrated the recent developments in the miniature and sub-miniature types of valve, and the 
various steps which have been taken to make valves increasingly reliable in operation. Dr. Thomson pointed out that valves are already completely reliable so far as home radio and television sets are concerned; at the same time, he emphasized the fact that the universal application of electronic machinery in offices, factories and in means of transport depends largely upon the reliability of electronic components.

The lecture closed with a brief speculation as to the future. While some may be of the opinion that an electronic valve or tube should never be used if it can be avoided, it is an essential item for high. speed operation. While this speed is still too low for many modern applications, it is likely that in the next half-century this speed of control will be exploited in all fields of activity.

An expression of thanks to the lecturers was made by Mr. C. W. Oatley, chairman of the Radio Section of the Institution, and by Sir Gordon Radley, vicepresident of the Institution; Sir Gordon remarked that if Sir Ambrose Fleming could have been present at this jubilee celebration of his invention, he would have been thrilled by the very large family that has sprung from the original and simple diode, and the variety of parts they have played in peace and in war.

R. L. SMith-Rose

\section{PHYSICAL RESEARCH LABORATORY, AHMEDABAD \\ By DR. K. R. RAMANATHAN Director}

A RESEARCH laboratory for the study of cosmic rays was started at Ahmedabad in 1947 by a private body called the Karmakshetra Educational Foundation. During the past seven years, with generous assistance from the Ahmedabad Education Society, the Government of Bombay, the Ministry of Scientific Research and the Atomic Energy Commission of India, the Physical Research Laboratory, as it is known, has steadily expanded and widened its scientific interests. The foundation stone of its new building was laid by Sir Chandrashekhar Venkata Raman in 1952 and the building was opened by the Prime Minister, Shri Jawahar Lal Nehru, on April 10, 1954.

The building is in the Gujarat University campus, and facing it are the laboratories of the Ahmedabad Textile Industry's Research Association (see Nature, Sept. 25, p. 578) and the Lalbhai Dalpatbhai College of Engineering. In a large field, west of the Laboratory, are a 72 -ft. wind tower, radio masts and an experimental hut for ionospheric research. The central wing of the Laboratory runs east to west and has two floors. Nine research rooms on the first floor and five on the ground floor are accommodated in this wing. For cosmic ray measurements, one of the research rooms on the first floor has a specially constructed light roof of aluminium. A conveniently accessible terrace on the first floor is used for observational work on the sun and the sky. 'The central wing of the Laboratory on the ground floor connects at one end to the library and a seminar room. The staircase is situated at the western end of the central wing, where there is also an experimental area with \& high ceiling. This is flanked by the workshop, the dark room, the stcre and a preparation section. Adjoining the workshop is a yard and a carpentry shop.

The initial research programme of the Laboratory was decided by the interests of its principal scientific workers : Prof. Vikram Sarabhai, who started the Laboratory, is concerned with studying the time variations of cosmic rays and the light they throw on the sources of cosmic rays; the present writer is interested in problems of atmospheric physics such as atmospheric ozone and its distribution, night airglow and problems of the ionosphere. The programme of the Laboratory at the moment comprises an integrated study of the different kinds of radiations which are received on the earth and their geophysical consequences. In order to carry out such a programme satisfactorily, two more Departments, one of Theoretical Physics and another of Radiophysics and Electronics, were added in 1949. With thirty research workers drawn from different parts of the country, the Physical Research Laboratory at Ahmedabad is now an established centre for advanced study and research in experimental and theoretical physies in western India.

Department of Atmospheric Physics. In India the Council of Scientific and Industrial Research has for many years supported a research scheme for the study of atmospheric ozone and the weather, and, with the co-operation of the India Meteorological Department, three ozone-measuring stations have been established at Delhi, Mt. Abu and Veraval. Work done in India has shown that the amount of ozone in low latitudes up to $20^{\circ} \mathrm{N}$. is small and nearly constant in different seasons, and is little affected by weather. On the other hand, in European latitudes, the amount of ozone is larger and more variable from day to day. In Indian latitudes north of $20^{\circ} \mathrm{N}$., during the months May-November, the amount of ozone continues to be small and steady, but increases markedly in winter. Between December and April there are large quasi-periodic increases of ozone associated with variations of highlevel winds in the upper atmosphere. Studies of the vertical distribution of ozone in the atmosphere that have been made over Delhi, Mt. Abu, Poona and Kodaikanal have established that the tropical troposphere which extends to nearly ten miles above the ground contains only small quantities of ozone, but that, as one goes to higher latitudes, more and more ozone comes down to lower levels. The change from the tropical type of ozone distribution to the extratropical type appears to take place in the region of high-level jet streams of westerly upper winds. The study of the correlated variations of atmospheric ozone at a number of places promises to throw light on the general circulation of the atmosphere at levels not otherwise easily accessible to observation.

An important discovery has resulted from careful ozone measurements made during moonlight. It has been shown that there is a daily variation in the amount of ozone in Indian latitudes, there being an excess of ozone during the night.

Besides the work on the ozone content of the atmosphere, a large number of radiosonde ascents have been made at Ahmedabad to study the daily and the day-to-day variations of temperature and humidity in the upper atmosphere. They have considerably increased our knowledge of the upper atmosphere over north-west India, and have also been of help in interpreting the corresponding variations of cosmic ray intensities. 